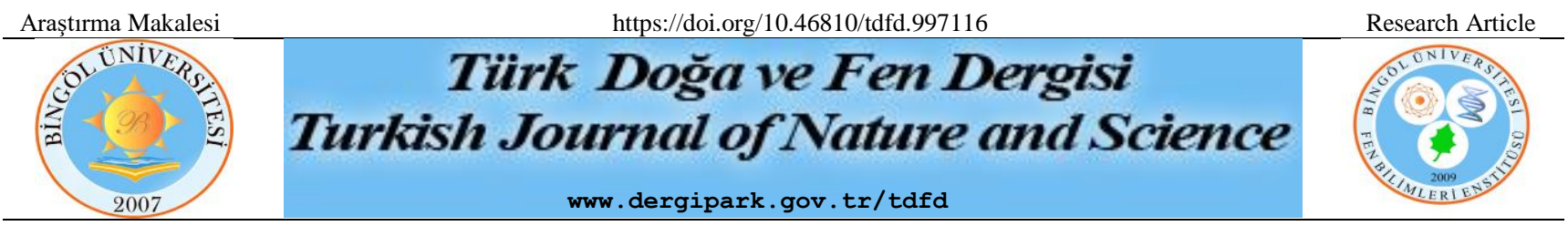

\title{
IoT Based Street Lighting and Computer Aided Control
}

\author{
Turgut ÖZSEVEN ${ }^{1 *}$, Merve Nur SAĞLAM ${ }^{2 *}$ \\ ${ }^{1}$ Department of Computer Engineering, Tokat Gaziosmanpasa University, Tokat, Turkey \\ ${ }^{2}$ Department of Mechatronic Engineering, Tokat Gaziosmanpasa University, Tokat, Turkey \\ Turgut ÖZSEVEN ORCID No: 0000-0002-6325-461X \\ Merve Nur SAĞLAM ORCID No: 0000-0003-0596-1639 \\ *Corresponding author: turgut.ozseven@gop.edu.tr
}

(Alınış: 17.09.2021, Kabul: 04.10.2021, Online Yayınlanma: 31.12.2021)

Keywords
Internet of
Things, Smart
City, LED
Lighting,
Smart Street
Lighting,
Lora,
ThingSpeak

\section{Keywords}

Internet of

Things, Smart

Lighting,

Smart Street

Lora,

ThingSpeak

\begin{abstract}
Traditional lighting systems have many disadvantages such as energy efficiency, failure tracking and lack of remote control. These disadvantages cause unnecessary energy consumption, extra labor, security threats and lack of follow-up. To overcome these problems, in this study, instead of traditional lighting, an IoT-based smart lighting prototype was developed and computerassisted control was performed. In order to ensure energy efficiency, the light intensity of the street lamps was adjusted according to the intensity by taking data from the motion sensors. Data such as fault tracking and density obtained from LED armature sensors were transferred to the cloud and controlled independently of the venue. Thus, the data on the cloud can be easily tracked through the ThingSpeak platform. With the visualized ThingSpeak web interface, the electrical power, current drawn, temperature value, ambient light value, location information, motion detection and remote switching of the LED armature can be done independently of the location. This study contributes to the literature on the usability and infrastructure of smart street lighting, both theoretically and practically.
\end{abstract}

\section{IoT Tabanlı Sokak Aydınlatması ve Bilgisayar Destekli Kontrolü}

\section{Anahtar}

Kelimeler

Nesnelerin

İnterneti,

Akıllı Şehir,

LED

Aydinlatma,

Akıllı Sokak

Aydinlatmas1,

Lora,

ThingSpeak
Öz: Geleneksel aydınlatma sistemlerinin enerji verimliliği, arıza takibi ve uzaktan kontrol eksikliği gibi birçok dezavantajı bulunmaktadır. Bu dezavantajlar gereksiz enerji tüketimine, ekstra iş gücüne, güvenlik tehditlerine ve takip eksikliğine neden olmaktadır. Bu sorunların üstesinden gelmek için bu çalışmada geleneksel aydınlatma yerine IoT tabanlı akıllı aydınlatma prototipi geliştirilmiş ve bilgisayar destekli kontrol gerçekleştirilmiştir. Enerji verimliliğini sağlamak için hareket sensörlerinden veri alınarak sokak lambalarının ışık şiddeti yoğunluğa göre ayarlanmıştır. LED armatür sensörlerinden elde edilen arıza takibi ve yoğunluk gibi veriler buluta aktarılarak mekandan bağımsız olarak kontrol edilmiştir. Böylece bulut üzerindeki veriler ThingSpeak platformu üzerinden kolaylıkla takip edilebilmektedir. Görselleştirilmiş ThingSpeak web arayüzü ile LED armatürün elektrik gücü, çekilen akım, sıcaklık değeri, ortam 1şık değeri, konum bilgisi, hareket algılama ve uzaktan anahtarlama, mekandan bağımsız olarak yapılabilmektedir. Yapılan bu çalışma akıllı sokak aydınlatmalarının kullanılabilirliği ve altyapısının oluşturulmasına yönelik gerek teorik gerekse de uygulama olarak literatüre katkı sağlamaktadır.

\section{INTRODUCTION}

With the development of technology, the planning, infrastructure systems and modern urbanization understanding of cities have begun to change and develop. Network connections, the internet of things, sensors and the first stages of the concept of smart city have started to come to the fore since the 1990s [1]. The concept of smart city is shaped by more innovative and technological developments day by day due to reasons such as people's demands, global warming, increasing population and increasing needs, and limited resources [2]. According to research by Anthopoulos, it is stated that there are more than 300 smart cities [3]. Cities that have been transformed into smart cities from scratch are Lusail (Qatar), Lavasa (India), Songdo (South Korea), Masdar (United Arab Emirates) [4]. 
Internet of Things (IoT) is expressed as the decision of the data collected by computers with their own calculation algorithms [5]. In this context, IoT constitutes the system that enables the communication of computers, digital machine systems, and elements expressed as objects to be transmitted over the network without the need for human interaction. In the concept of IoT, the phenomenon characterized as a thing is devices and sensors. In order for an thing to be accessible from anywhere in the world and to be considered an thing, it must contain a unique identity name, communicate with other devices, and also contain a sensor [6]-[8]. The advantages of IoT are space-time independent device tracking, use in places where there is a risk of life safety, database connection and cost savings. The disadvantage is that the data has security and privacy problems [9]. IoT, which provides low power consumption, generally uses Wi-Fi, Bluetooth, RFID, NFC, UWB and LTE technology as communication protocol [10], [11].

Another technology that provides data transmission between long distances is LoRa (Long Range). Long Range Wide Area (LoRaWAN) is a wireless communication technology with low power consumption and wide transmission distance $(5 \mathrm{~km} \sim 15 \mathrm{~km})$ for the realization of LoRa network connections. The transfer of the data received from the LoRas to the server is carried out through the multi-channel gateway. The gateway processes the data by capturing the broadcast radio frequencies, thereby extending the LoRaWAN coverage [12].

Light-emitting diodes (LED) are seen as a very important solution for the future as a light source due to reasons such as climate changes in the world, limited resources, and rapid increase in energy prices. Halogen lamps, fluorescent lamps and high-pressure mercury lamps with high energy consumption and low efficiency are gradually removed from the market and replaced by LED lighting. Unlike existing light sources, LEDs are not lamps, but consist of electronic chips made of special semiconductor material. In the 2000s, the development of LED as an alternative to traditional light sources has accelerated [13]. The color rendering value, which ensures that the colors of the LEDs are perceived as real as possible, is 85 and above, and the objects are illuminated in a realistic way when compared to traditional light sources [14]. Compared to traditional lighting elements, LED lamp lighting is more advantageous in terms of high power and efficiency [15], [16]. LED lighting consumes less energy at the same power value [17]. The disadvantages of LED lighting are the high initial installation costs when used for street lighting. LEDs operating in the range of voltage values do not light when this operating voltage is low, and they are damaged if the operating voltage is high. These voltage adjustments require external current regulators and resistors in series. Considering the effects on environmental pollution, while the light source obtained from the diodes in the LEDs provides harmless lighting to the environment, the creation of a light source with fluorine gas and mercury vapor in fluorescent lighting is harmful for the environment.
Collins et al. [18], provided the dimming of the armature depending on the number of vehicles passing per hour on a road that provides real-time lighting control in England. According to the report obtained at the end of one year, it was revealed that $24 \%$ of electrical energy was saved. Even though there is a high installation cost of making street lighting smart with sensors, energy consumption will decrease [19]. In the 'Smart City Roadmap' report, which Deloitte and Vodafone work together, it is aimed to use resources economically and to achieve efficiency in smart city studies. In the smart street lighting application, the saving in electricity consumption in Oslo is expressed as 70\% [20]. With the 'GrowSmarter' project within the scope of the Horizon 2020 program, smart city solutions have started to be implemented in 12 different areas such as smart street lighting and smart electricity method with an investment of 24.8 million Euros in the cities of Cologne, Stockholm and Barcelona [4]. According to the comprehensive 'Smart City Market Entry' report for the GrowSmarter project, it has been stated that the sensors placed in certain parts of the city in the smart street lighting system have an important share in energy efficiency and economic returns [21]. In the smart street lighting work of the GrowSmarter project, which was invested with the goal of sustainable urban mobility and low energy zone, pedestrian paths illuminated with LEDs were built. In the study, remote control was provided with motion and light sensitive sensors based on IoT. The sensors, which are active when motion is detected, provide 50\% electricity savings through LED lamp lighting [22].

This study aimed to contribute to smart lighting systems in smart city applications. For this purpose, an IoT-based smart lighting prototype has been developed and by making the data received from the sensors meaningful, it can be remotely controlled with a wireless network structure, monitored instantly and data is stored. The motion density, malfunction and electricity consumption status, location information obtained thanks to the sensors were recorded with IoT and remote control was provided with the ThingSpeak [23] web interface. This study contributes to the literature on the usability and infrastructure of smart street lighting, both theoretically and practically.

In the next section of the study, the materials and methods used for the development of the prototype are given. In the third section, the results obtained because of running the prototype are included. In the last section, there is a discussion section in which the outputs obtained, and traditional methods are compared.

\section{MATERIAL AND METHODS}

In this study, IoT-based smart lighting prototype was developed and computer-assisted remote control was provided. Using a 100W SMD LED panel, temperature, motion, light intensity sensors placed on the lighting and fault status information were transferred to the cloud over long distances via LoRa, a wireless network 
technology. Since the high temperature will reduce the life of the LED lighting, the temperature value of the lighting can be read instantly and monitored over the system. Energy efficiency is planned by controlling the lighting with PWM. The created prototype was controlled remotely via the ThingSpeak web interface. The following sections detail the materials and methods used for prototyping and computer aided control.

\subsection{Atmega328P Microcontroller}

Since Atmega microcontroller has Harvard and Reduced Instruction Set Compute (RISC) architecture, the processing speed is high. This microcontroller, which has low power consumption, contains SRAM, flash, EEPROM in different sizes. It has an operating speed of up to $20 \mathrm{MHz}$. While it draws $1.5 \mathrm{~mA}$ during active operation, it draws a minimum of $0.1 \mu \mathrm{A}$ in sleep mode. It can be programmed with UART, SPI, I2C communication protocols. Atmega328p, which has 28 pin outputs, 23 are input output pins. More than one command can be controlled with an Atmega. It has an operating voltage of $1.8 \mathrm{~V} \sim 5.5 \mathrm{~V}$ [24].

\subsection{LoRa}

With IoT, wireless sensor network is widely used. LoRaWAN is a free network protocol regulated by the LoRa Alliance company [25]. This network acts as a gateway for LoRa data transmission. LoRa technology is suitable for use over long distances. Transmission speed and energy consumption are relatively lower than other wireless communication chips [26].

LoRa used for the prototype is E32-TTL from Ebyte Company. It provides data transmission over the UART communication protocol in the $433 \mathrm{MHz}$ frequency band with an operating voltage range of $2.8 \mathrm{~V} \sim 5.5 \mathrm{~V}$ DC. This LoRa is preferred because it transmits data over long distances compared to other wireless transmission protocols due to the large distance between each lighting in street lighting.

\subsection{Esp8266 (Wi-Fi Module)}

ESP Wi-Fi Module is a module that can connect to the internet wirelessly via serial communication. It is often preferred in IoT applications. The ESP8266 can connect to an existing internet network, and it also spreads its own internet network and allows things to connect to this network. UART communication protocol is used with $\mathrm{RX} / \mathrm{TX}$ pins on this Wi-Fi module with ceramic antenna with an operating voltage of $3 \mathrm{~V} \sim 3.6 \mathrm{~V}$. ESP8266, which has low power consumption like LoRa, consumes $20 \mu \mathrm{A}$ in sleep mode and $80 \mu \mathrm{A}$ during normal use. It has $32 \mathrm{Bit}$ $80 \mathrm{MHz}$ processor, 4MB flash, 40KB RAM [27].

\subsection{LED Panel}

In the prepared prototype, a $100 \mathrm{~W}$ LED panel with an operating voltage of $30 \mathrm{~V} \sim 36 \mathrm{~V}$, shown in Figure 1, was used. The LED panel consists of 200 SMD LEDs, 20X10. To prevent overheating, the LED panels placed on the printed circuit boards called aluminum PCBs provide some distribution of the heat on the luminaire.

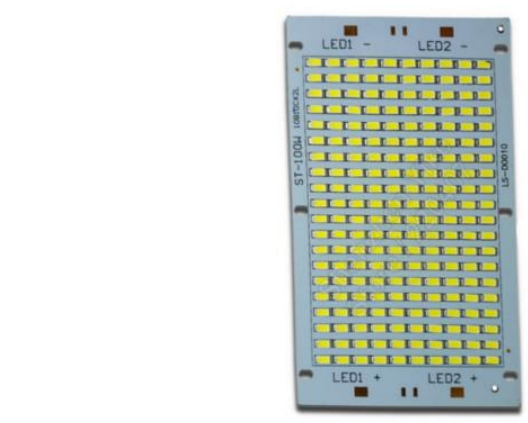

Figure 1. LED panel used in prototype

\subsection{MOSFET}

In the prototype, P-type mosfet with incremental channel is used for the $32 \mathrm{~V}$ voltage applied to the power input of the electronic circuit board. The reason for using the incremental channel $\mathrm{P}$ type mosfet is that it is a type of mosfet that does not pass current when it is closed, which is the opposite of the working logic of the reducing channel mosfet. That is, as long as no voltage is supplied from the gate terminal, there is no current flow from the drain and source terminals. Thus, the mosfet does not transmit. For this mosfet to conduct, when the voltage is applied positively, the area where the current will flow expands and thus, current flow is ensured between the drain and the source [28]. Mosfets are used to dim the lighting panels on the circuit because they control the voltage entering the input. In the electronic circuit, 6.6A P-channel mosfet with $100 \mathrm{~V}$ input voltage with product code IRFR9120NTRPBF is preferred.

\subsection{Sensors Used in Prototype}

Motion sensors, also known as Pyroelectric Infra-Red (PIR), work with the logic of reflecting signals from the body heat radiation of humans and living things, and signals of different wavelengths hitting the object and reflecting [29]. The HC-SR501 PIR motion detector with an operating voltage of $5 \mathrm{~V}-20 \mathrm{~V}$ and a power consumption of $65 \mathrm{~mA}$ was used to determine the dimming levels of the LED panels depending on the motion in the prototype.

For the prototype, ACS712 current sensor was preferred in accordance with the electrical current values. It will be used to control the faults caused by the fault status of the LED panels or the excessive current draw in the system. It acts as a protection in electronic circuits by preventing damage to other electronic elements in high current or voltage values applied to its input. This sensor, which has an operating voltage of $4.5 \mathrm{~V} \sim 5.5 \mathrm{~V}$, measures current up to $\pm 5 \mathrm{~A}$. This sensor has a sensitivity of $185 \mathrm{mV}$ and the voltage value measured at idle $(0$ ampere) is $2.5 \mathrm{~V}$ [30]. In line with this information, the voltage value measured at no-load is subtracted from the measured value via this current sensor, which gives an analog output. The value of each $185 \mathrm{mV}$ obtained corresponds to a value of $1 \mathrm{~A}$. 
Light Dependent Resistors (LDRs) are frequently used in street lamps, control equipment, night lighting lamps. The LDR sensor is used in the prototype to open and close the LED panel sensitively to daylight, depending on the light intensity.

Real Time Clock (RTC) is used to turn the LED panel on and off at desired times. With RTC, the time zone can be followed instantly and continuously. DS1302 RTC integrated with $2 \mathrm{~V} \sim 5 \mathrm{~V}$ operating voltage belonging to Maxim company is used. It works over the I2C communication protocol. RTC ICs are used with an external battery so that the time data stored in SRAM is not deleted when the power is cut. An external $32.768 \mathrm{KHz}$ crystal should be used to prevent time shifts in the DS1302 IC [31].

Voltage regulators are preferred to adjust the voltage on the electronic circuit board to the operating voltage of the electronic component to be used. Since the voltage supply of the PCBs is realized through the $32 \mathrm{~V}$ transformer, this voltage must be adjusted on the board. For this reason, regulators that are suitable to be used are LM2576 Adj (adjustable voltage voltage) and AMS1117. While selecting the regulator, the PCB design was carried out considering the amount of current to be passed over it and the auxiliary electronic components (resistor, capacitor) required for the adjustment of the appropriate voltage. Negative Temperature Coefficient (NTC) thermistor is used to determine the temperature of the LED panel.

Measuring the voltage on the electronic board is based on the voltage divider principle. Monitoring the voltage value applied to the system ensures the correct operation of the electronic system and at the same time, it ensures that possible situations and malfunctions are prevented by controlling the excessive voltage draw over the power supply, and the detection of power cuts. In the prototype, voltage sensing is realized by means of a resistor.

\subsection{Design Stages}

Smart lighting prototype PCB boards are drawn as 2 layers. The prototype consists of three separate PCBs. These are the main electronic board, the sensor board and the SIM808 GSM electronic board. Figure 2 shows the schematic of the sensor PCB in the KiCad [32] program. There are Atmega328p microcontroller, voltage regulator, current sensor, RTC, LDR and MOSFETs and other electronic elements on this board. Figure 3 shows the footprint and 3D design of the PCB with the sensors.

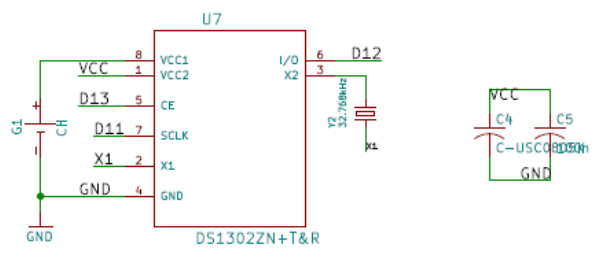

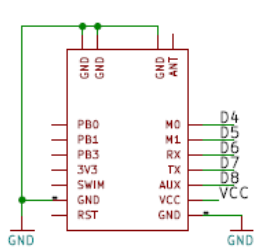
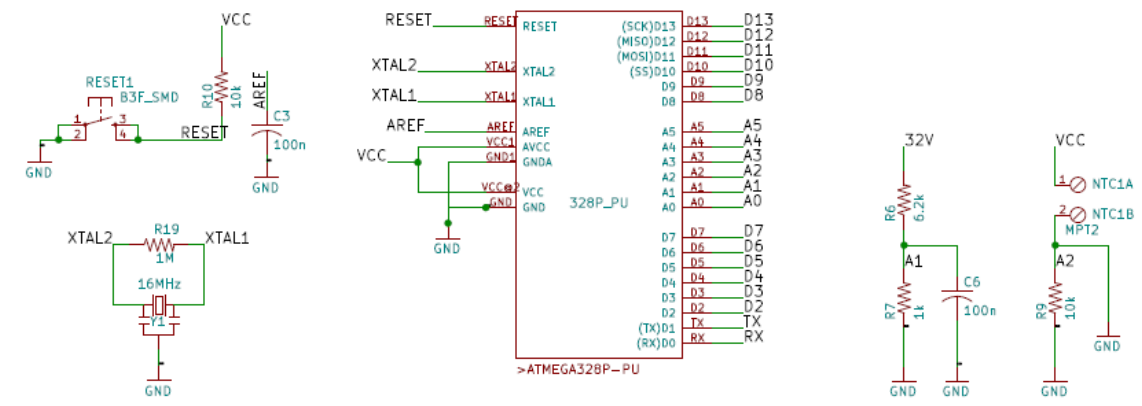
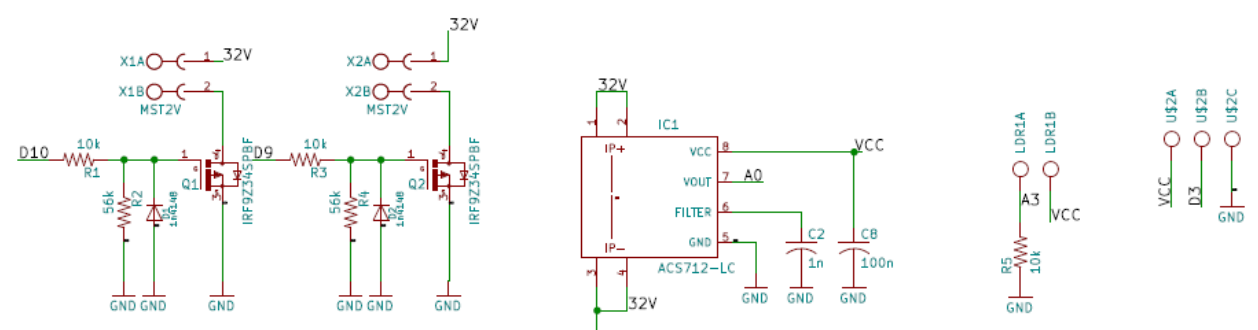

Figure 2. Smart Lighting Sensors and Lora PCB Module Schematic 

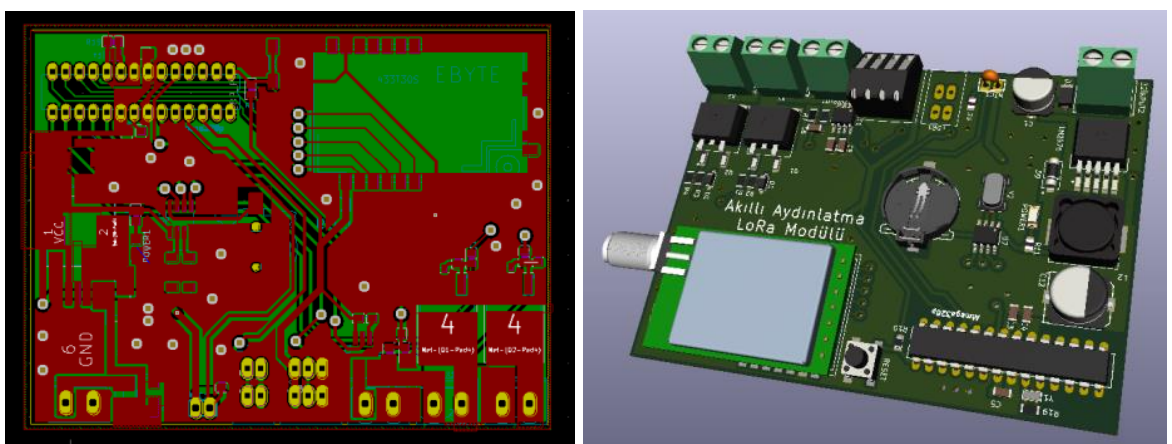

Figure 3. Smart Lighting Sensors and Lora PCB Module Footprint and 3D Design

The Wi-Fi module given in Figure 4 is designed to receive the data from the sensors and transfer them to the server wirelessly. The $32 \mathrm{~V}$ voltage received from the transformer was used in the necessary voltage adjustments for the LoRa and ESP8266 module. An adjustable LM2576 regulator is used to reduce the voltage from the transformer to the appropriate operating voltage of LoRa. In this regulator, the necessary mathematical calculations for the voltage to be $4.2 \mathrm{~V}$ were considered, considering the rules in the information sheet, and the appropriate auxiliary resistance values were determined and included in the system. Figure 5 shows the footprint and 3D design of the wi-fi module. In Figure 6, application images of the prototype are given.
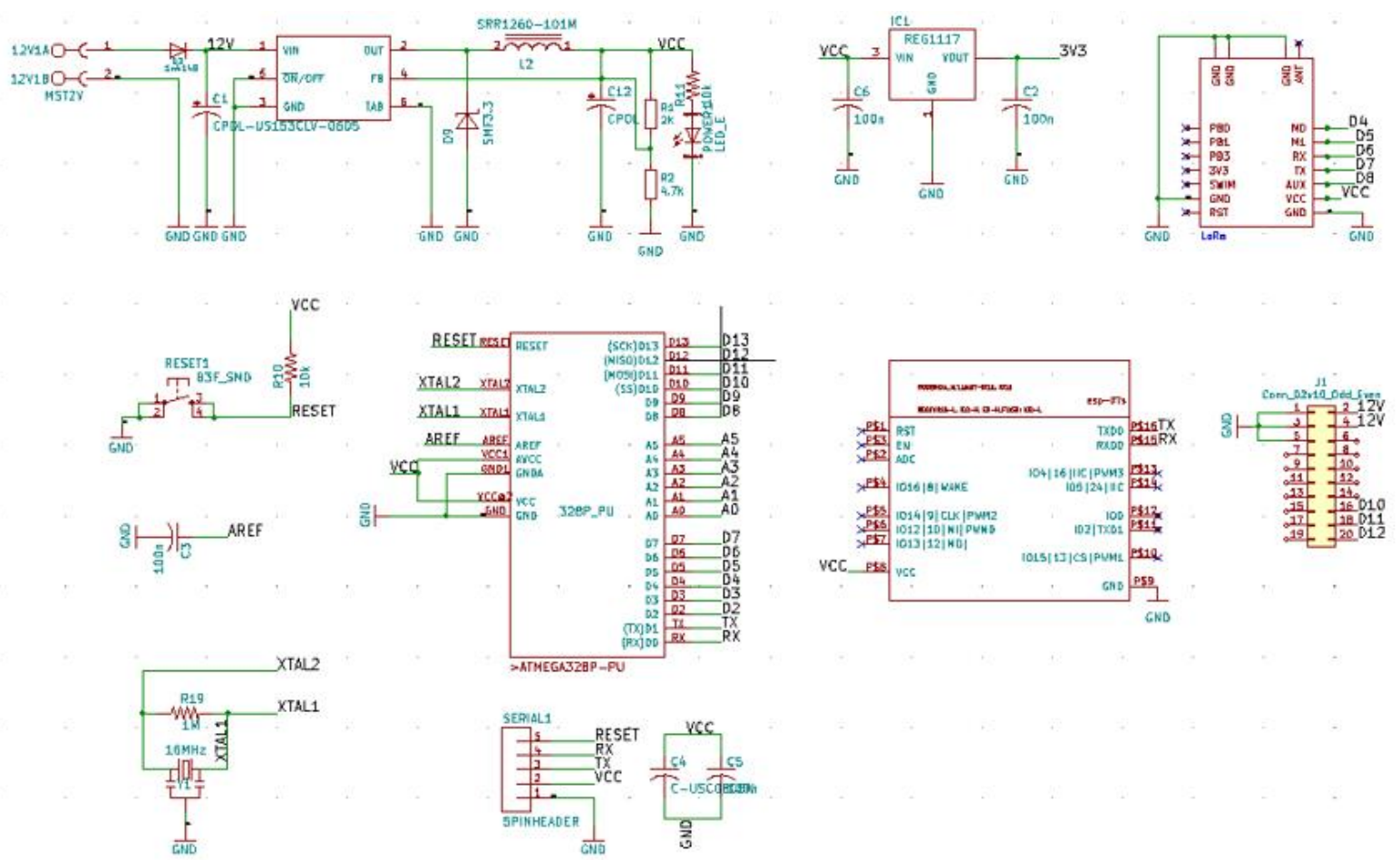

Figure 4. Schematic of Smart Lighting Wi-Fi Module
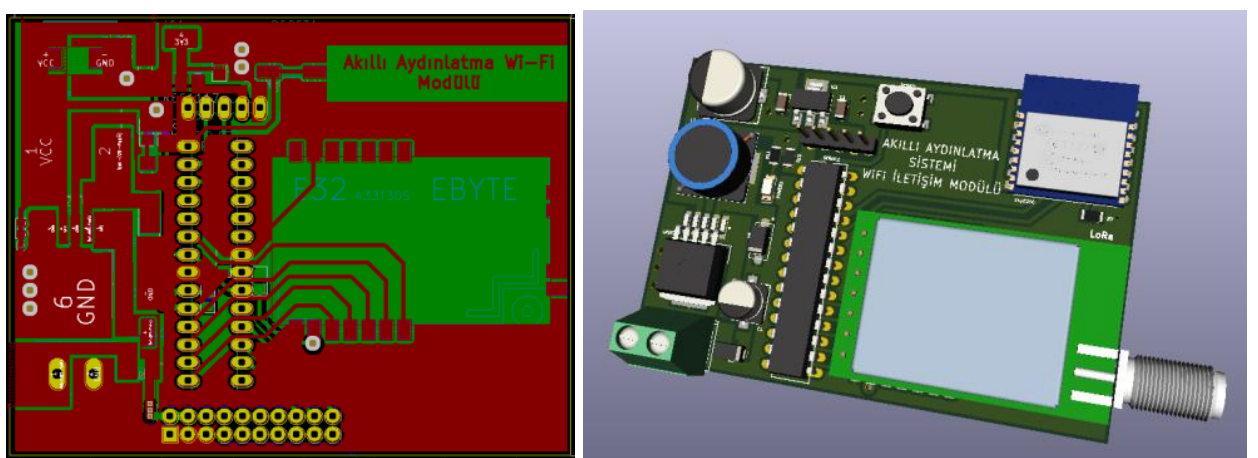

Figure 5. Footprint and 3D Design of Wi-fi Module 

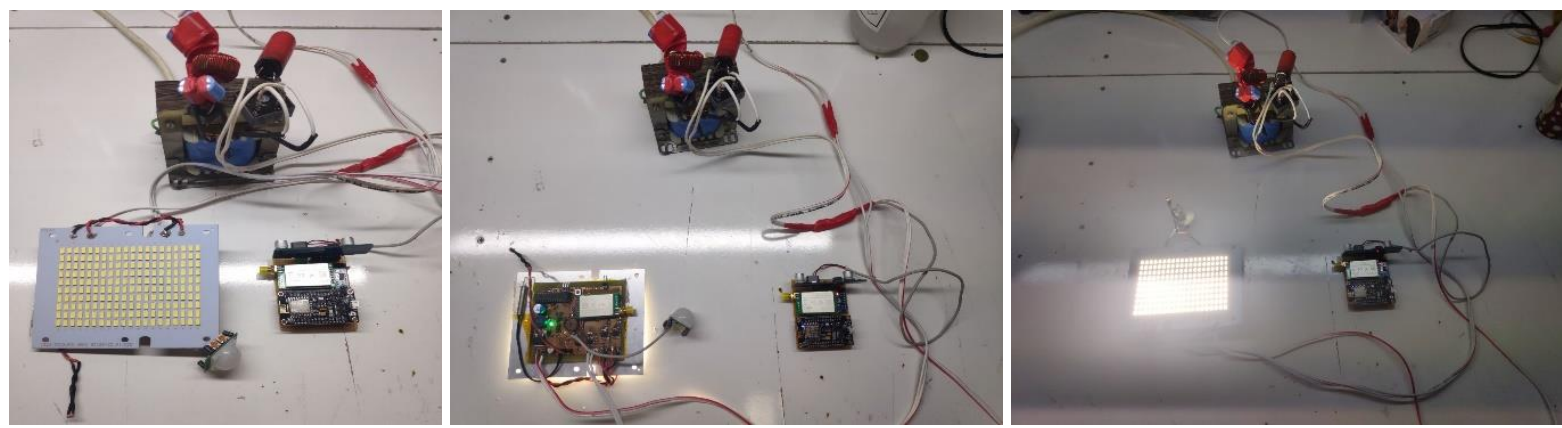

Figure 6. Images of the Smart Lighting Prototype

\subsection{Transmission and Control of Data to the Server}

Message Queuing Telemetry Transport (MQTT), which stands for telemetry transport, provides machine-tomachine communication and is an important messaging protocol for IoT. In other words, MQTT provides the opportunity to control the data it receives from the things that need to be remotely controlled via the server [33]. The LoRa module, which acts as a transmitter card, transmits the collected data to the wi-fi module. The electronic card is connected to the MQTT server with the ESP8266 internet module on it. Thus, the data received from devices such as computers, phones, tablets, and sensors can be accessed and controlled from anywhere. The necessary codes for programming the ESP8266 wifi module and Atmega328 processor were written in the arduino integrated development environment.

After the prototype development stage, it was ensured that the electronic cards communicate with each other and be followed over the server. The data obtained from the sensor networks were recorded in the database via the cloud based ThingSpeak platform and checked online. The reasons why ThingSpeak application is preferred are being able to follow the data in real time and instantaneously, reporting the obtained results, and being able to analyze it through MATLAB graphic designs. The data received from the sensors on the realized smart lighting prototype can be followed instantly on this platform.

By adding API Keys and channel ID to the software on ThingSpeak, each sensor can be matched to a different area and controlled with an appropriate graphical interface design. These different fields are called 'Field'. In each opened channel, data obtained from eight sensors at the same time is visualized. The general view of the values obtained from the sensors assigned to the fields is given in Figure 7.

The data saved in the database can be stored in ThingSpeak free of charge or exported in XML, JSON,
CSV formats, which are different standards where objects are used to share data among themselves.

\section{RESULTS AND DISCUSSION}

In the smart lighting prototype, which is the subject of the study, LoRa was used as the most suitable wireless network structure due to its advantages such as transmission speed, affordable cost, unlimited message reading capacity, and wide coverage. The developed prototype has been designed as close to reality and can be used easily in all areas.

Among the problems encountered in traditional street lighting, problems such as the lighting that comes on before its time, the lack of sufficient lighting level during the time when the movement is high, the failure of the malfunctioning street lighting not to be noticed from afar have been solved with the developed prototype. With the PIR sensor included in the system, energy is saved by performing full efficiency or dimming depending on the intensity of movement. Another energy-saving area is the use of LED panels, which are formed by combining more than one LED, which creates high luminous flux with minimum energy consumption, instead of traditional lighting. Thus, a brighter illumination level has been achieved at low cost. With the system being made smart, the LDR sensor is activated, and lighting is provided in the time periods when lighting is required depending on the ambient light.

With the IoT, the data collected from the wireless network structures are transferred to the server and can be easily accessed at the desired time interval. The values obtained from the sensors can be controlled with the IoT infrastructure via ThingSpeak, which is a cloudbased web interface. Thus, a smart lighting system in accordance with the smart city concept that can decide on its own has been realized. 


\section{$\square$ ThingSpeak ${ }^{m m}$ Channels - Apps - Devices- Support- Commercial Use How to Buy MN}

\section{Channel Stats}

Created: about a monthago

Last entry: less than a minute ago

Entries: 20285
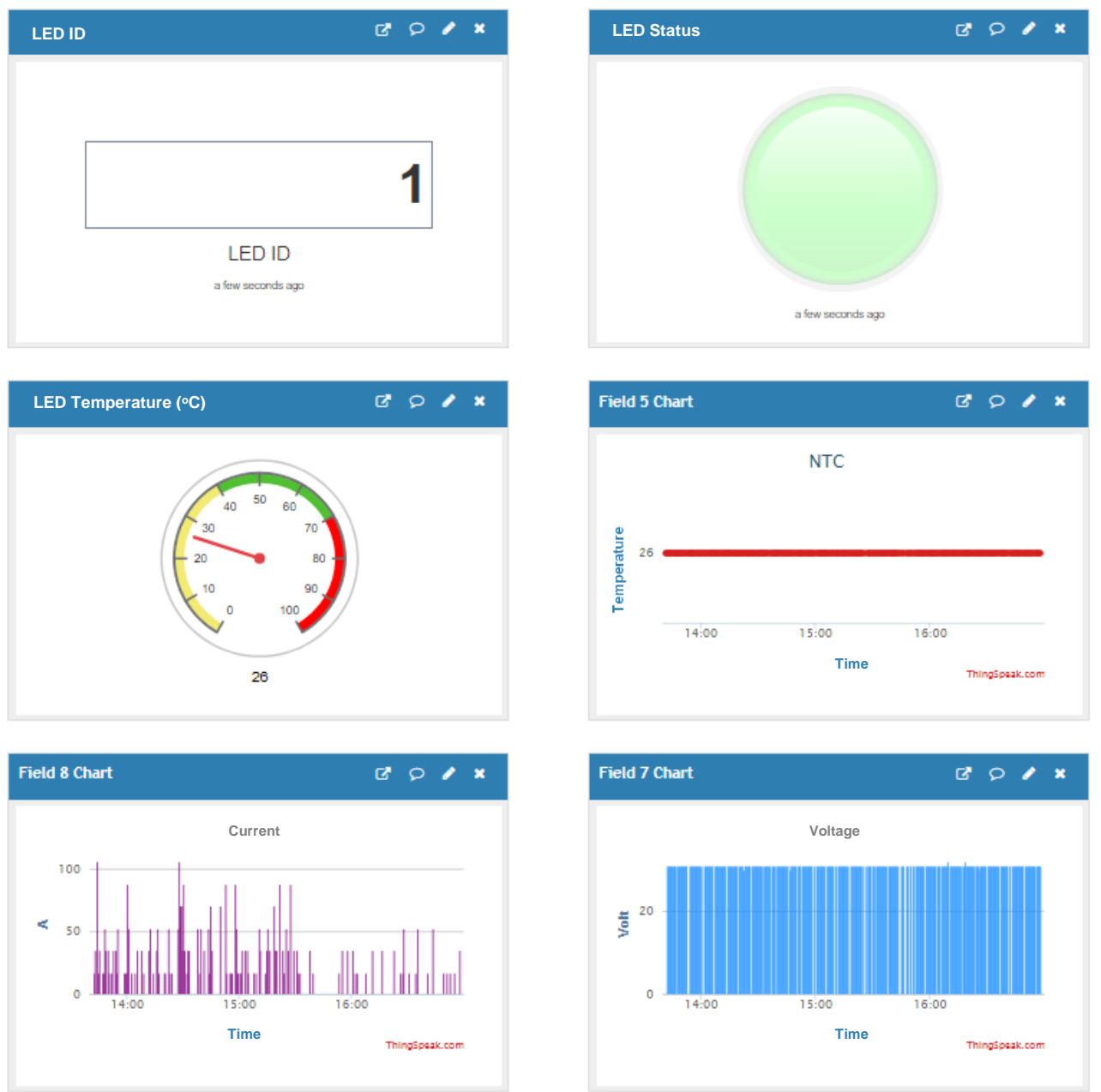

Figure 7. ThingSpeak Interface
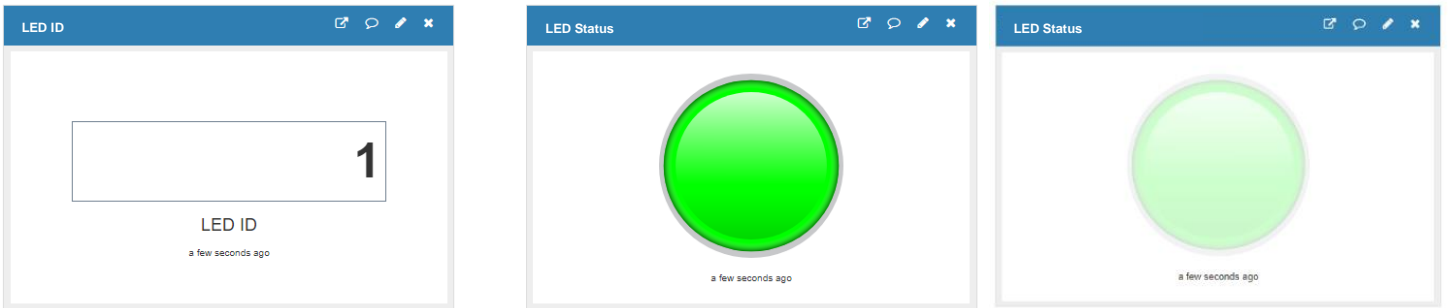

Figure 8. LED ID and Active Status (With and Without Illumination)

The software of the processors on the modules are made with the arduino application written in $\mathrm{C}$ and $\mathrm{C}++$ languages. The data coming from the sensors were also checked on the arduino virtual screen and it was determined that there was no data loss in the data transferred to ThingSpeak.

The control of the LED Panel is followed by the ID number assigned to it and the instantaneous flashing control with the visuals given in Figure 8. The LDR sensor activates and illuminates when the operating time of the LED Panel, which is included in the operating logic of the system and is included in the software, is active and at the same time, in cases where early lighting should be provided due to the darkening of the air.

Overheating of LED panels both damages the LEDs and poses a danger to other electronic components. The temperature value at which the LEDs will fail is $70^{\circ} \mathrm{C}$, and when it exceeds this value, the system switches to protection and automatically stops working. Therefore, the instantaneously controlled temperature value changes between $40^{\circ} \mathrm{C}$ and $42^{\circ} \mathrm{C}$ at the highest when the LED is active. During the daytime, the temperature values are around $26^{\circ} \mathrm{C}$. In Figure 9, the visual of the temperature status of the LED panel is given. 

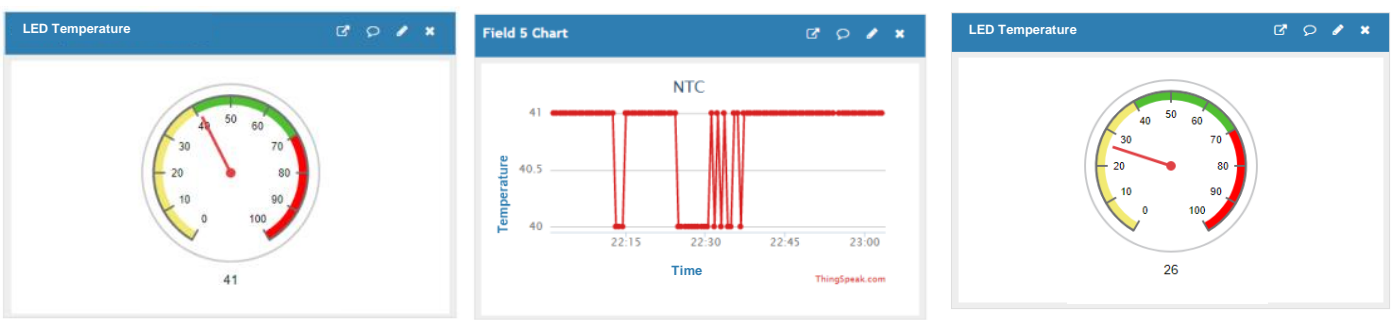

Figure 9. Temperature Status of LED Panel with Lighting On and Off

The instantaneous and weekly measurement results of the temperature values of the LED lighting are given in Figure 10.

The current values given in Figure 11 show the current drawn by the prototype from the electronic circuit. Values controlled instantly or in the desired date range via the ThingSpeak web interface indicate how much current the system draws in which time. ACS712 current sensor measures the current drawn from the system and protects the system against high current draw in case of failure. The voltage graph given in Figure 12 shows the voltage value drawn by the LED lighting.

Working depending on daylight, the LDR sensor controls the darkening of the air and the early darkening in bad weather conditions. Thus, the system works even in the time when lighting is mandatory before the clock arrives. Images of the LDR status are given in Figure 13.
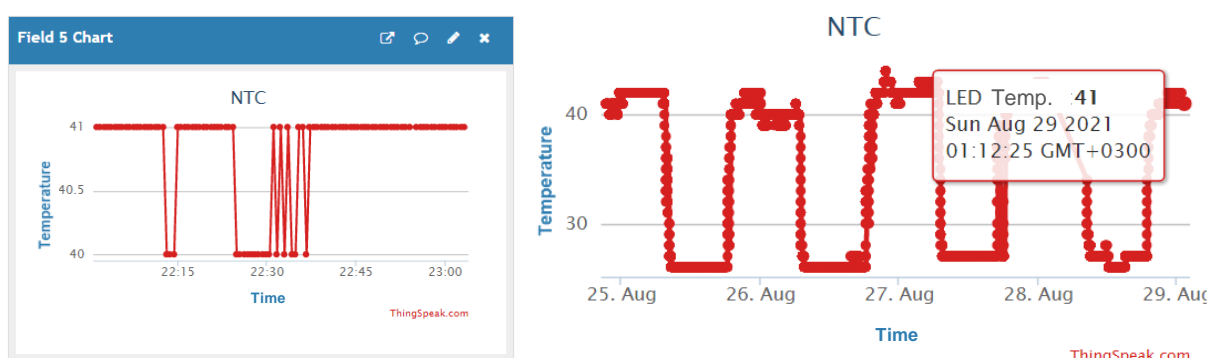

Figure 10. ThingSpeak Instant and Weekly NTC Status

Current
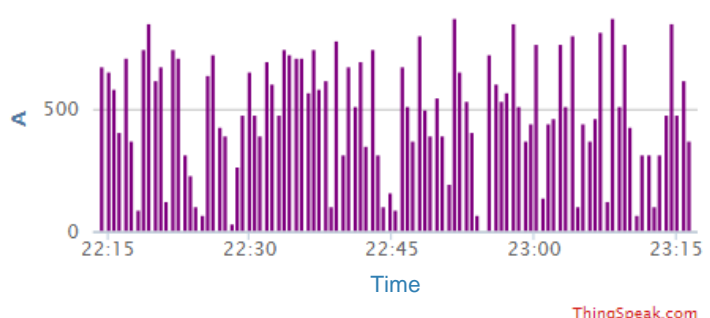

Figure 11. ThingSpeak Instant and Weekly Current Status

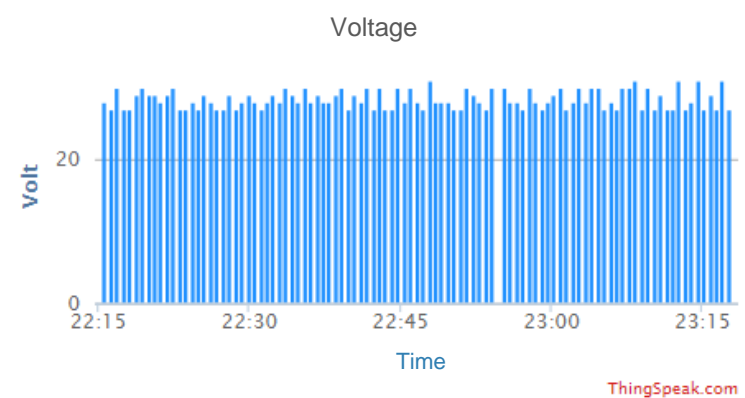

Figure 12. ThingSpeak Voltage Status

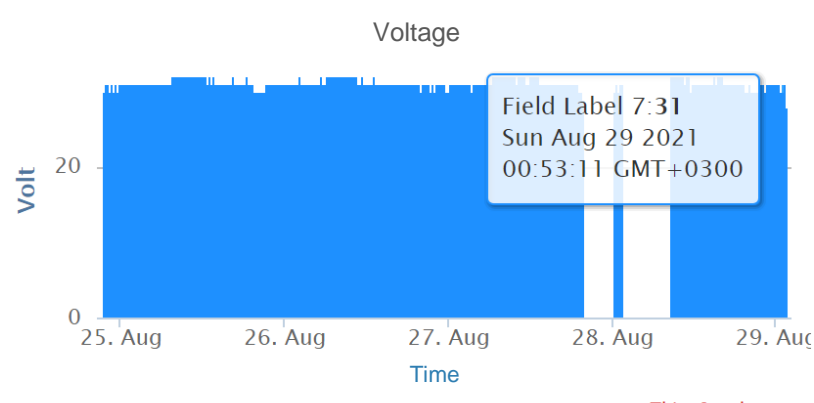

ThingSpeak.com

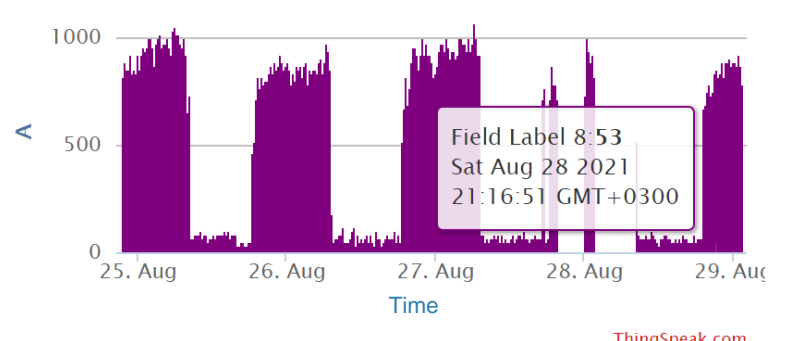


LDR

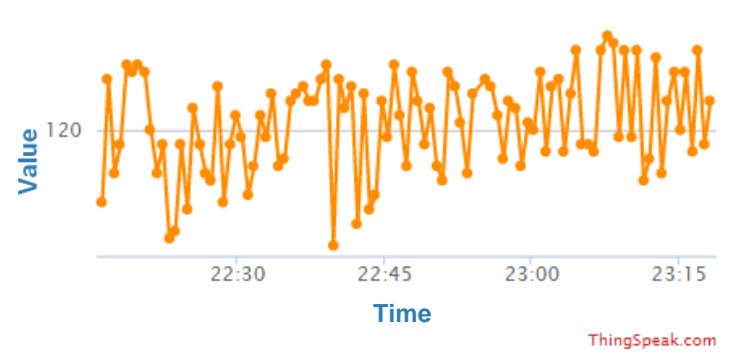

Figure 13. ThingSpeak LDR Status

PIR

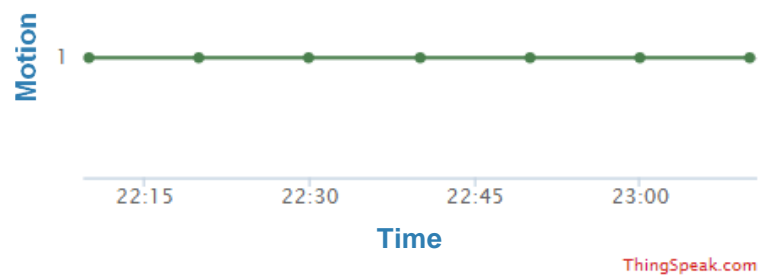

Figure 14. ThingSpeak PIR Status

In the prototype prepared, the LED lighting level changes according to the motion situation. In cases where there is no movement, it is aimed to save energy by providing 50\% dimming between 00:00 and 04:00 at night. In this time range, only when motion is detected, LED lighting works with $100 \%$ efficiency. Thus, LED lighting, which is intended to be used for street lighting, is included in the system when it detects a vehicle or living thing outside. Images of the motion state are given in Figure 14. Thanks to the location adding feature in the ThingSpeak web interface, the location of the LED lighting has been added to this platform.

\section{DISCUSSION}

The aim of the study is to obtain a good light source with low energy consumption. The developed LED smart street lighting system has been made self-deciding with sensors and electronic components. The targeted findings for smart lighting have been successfully realized. Electronic hardware and software areas of the prototype were followed instantly and for a long time and no problems were encountered.

With the LoRa wireless communication network, even from very long distances, the data from the sensor is transferred to the cloud base without loss. The use of the ThingSpeak application, which provides the opportunity to access the recorded data either instantly or in the past, has made the smart lighting prototype more useful and understandable.
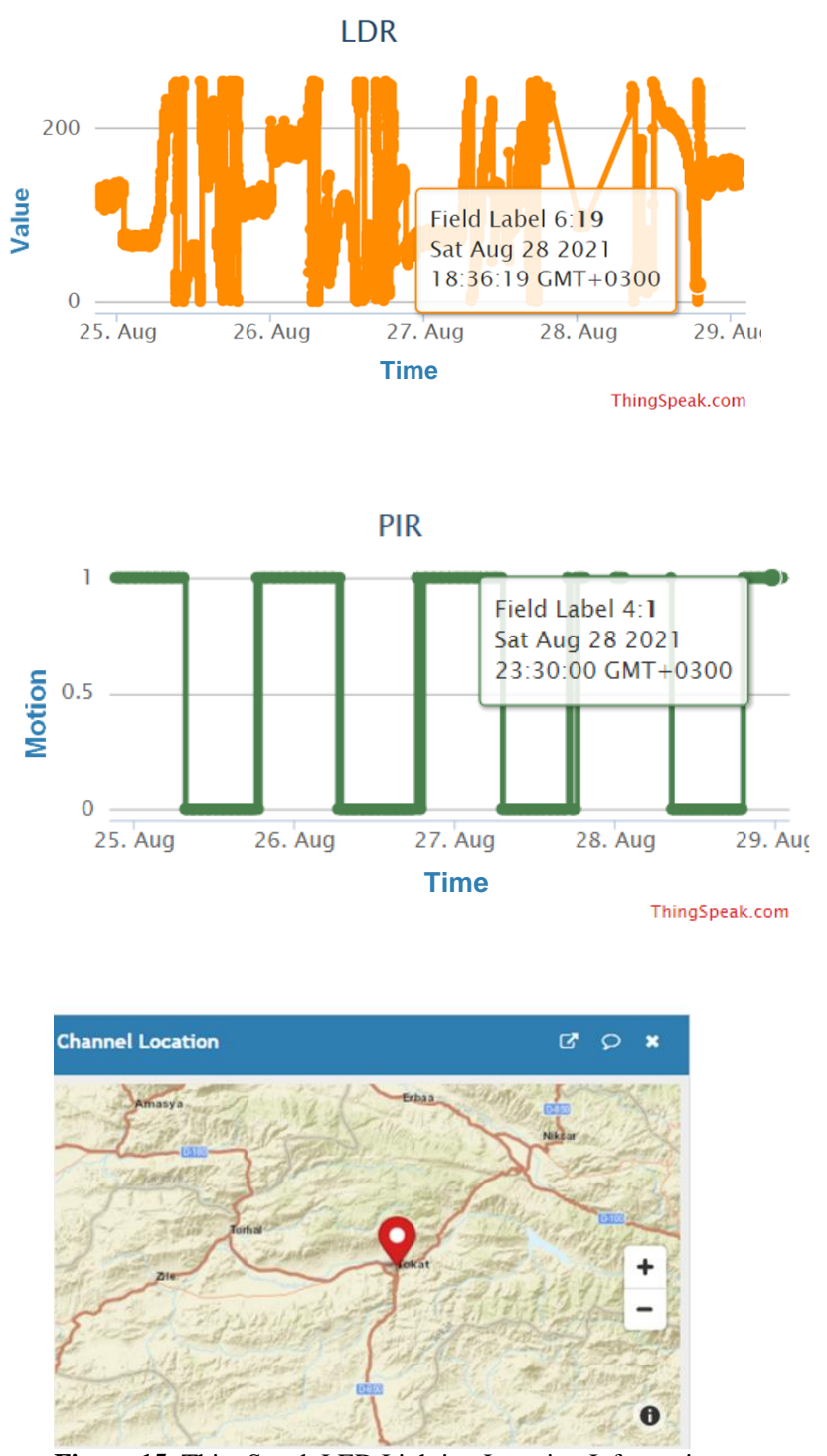

Temperature measurement was made with the NTC sensor placed on the LED lighting panel and it was determined that the temperature values were normal. However, for the smart lighting prototype to be made in long-term usage areas, a separate design can be added to the system to provide cooling, and thus the lifetime of the LEDs can be extended.

\section{REFERENCES}

[1] Örselli E, Akbay C. Teknoloji ve kent yaşamında dönüşüm: akıllı kentler. International Journal of Management Academy. 2019;2(1): 228-241.

[2] Ateş M, Önder D. E. The Concept of 'Smart City'and Criticism within the Context of its Transforming Meaning. Megaron. 2019;14(1): 41.

[3] Anthopoulos L. G. Understanding smart cities: a tool for smart government or an industrial trick. Springer; 2017.

[4] Gürsoy O. Smart City Approach and It's Implementation Feasibility for the Metropolitan Cities in Turkey [dissertation]. Ankara: Hacettepe University; 2019.

[5] Ashton K. That "internet of things" thing. RFID journal. 2009;22(7):97-114. 
[6] Commission F. T. Internet of things: Privacy \& security in a connected world. Washington, DC: Federal Trade Commission. 2015.

[7] Miorandi D, Sicari S, De Pellegrini F, Chlamtac I. Internet of things: Vision, applications and research challenges. Ad hoc networks. 2012; 10(7): 14971516.

[8] Sha K, Wei W, Yang T. A, Wang Z, Shi W. On security challenges and open issues in Internet of Things. Future Generation Computer Systems. 2018; 83: 326-337.

[9] Jalali M. S, Kaiser J. P, Siegel M, Madnick S. The internet of things promises new benefits and risks: a systematic analysis of adoption dynamics of IoT products. IEEE Security \& Privacy. 2019; 17(2): 39-48.

[10] Al-Fuqaha A, Guizani M, Mohammadi M, Aledhari M, Ayyash M. Internet of things: A survey on enabling technologies, protocols, and applications. IEEE communications surveys \& tutorials. 2015; 17(4): 2347-2376.

[11] Ghaffari K, Lagzian M, Kazemi M, Malekzadeh G. A socio-technical analysis of internet of things development: an interplay of technologies, tasks, structures and actors. Foresight. 2019.

[12] Thomas A, Eldhose N. Heterogeneous LPWAN Communication for Electric Vehicle Charging Infrastructure. IJITEE. 2019; 9(2): 2060-2067.

[13] 'LED: The Light of the Future. [Internet]. licht.de; [cited 2021 Sep. 17]. Available from: https://fdocuments.in/document/lichtwissen-no-17led-the-light-of-the-future.html.

[14] Aman M. M, Jasmon G. B, Mokhlis H, Bakar A. H. A. Analysis of the performance of domestic lighting lamps. Energy policy. 2013; 52: 482-500.

[15] Hinov N, Tsankov $P$, Ibrishimov H. Innovative LED lighting. International Conference on Creative Business for Smart and Sustainable Growth, CREBUS 2019; p. 1-5.

[16] Özçelik M. A, Yılmaz M. Comparison of Fluorescent and Normal LED Illumination in terms of Energy Efficiency with Smart LED System Proposed Zone Controlled Room in Daylight. ElCezeri Journal of Science and Engineering. 2019; 6(2): 270-281.

[17] Akyazı Ö, Şahin E, Kahveci D. C. Smart Street Lamp Design and Application with PV Panel and Grid Integration. European Journal of Science and Technology. 2019; Special Issue, pp. 356-360.

[18] Collins A, Thurrell T, Pink R, Feather J. Dynamic dimming: The future of Motorway lighting?. Lighting Journal. 2002;67(5): 25.

[19] Erkin E, Yurtseven M. B, Güler Ö, Onaygil S. Led Panel Armatürlerin Ofis Aydınlatmasında Retrofit Amaçlı Kullanımının İncelenmesi. VII. Ulusal Aydınlatma Sempozyumu. 2013. pp. 15-21.

[20] Deloitte-Vodafone Akıllı Şehir Yol Haritası [Internet]. Deloitte-Vodafone; 2021 [cited 2021 Sep. 17]. Available from: http://www.vodafone.com.tr/VodafoneBusiness/iot/ pdf/ akilli-sehir-yol-haritasi
[21] Tapia A, Carrasco C, Ricart J. E, Piedra J, Rodríguez M, Franca P. Smart City Market Introduction. 2020.

[22] GrowSmarter Project [Internet]. European Commission; 2017 [cited 2021 Sep. 17]. Available from: https://cordis.europa.eu/project/id/646456

[23] IoT Analytics - ThingSpeak Internet of Things [Internet]. 2021 [cited 2021 Sep. 17]. Available from: https://thingspeak.com/

[24] ATmega328P Datasheet [Internet]. 2021 [cited 2021 Sep. 17]. Available from: http://ww1.microchip.com/downloads/en/DeviceDo c/Atmel-7810-Automotive-MicrocontrollersATmega328P_Datasheet.pdf

[25] LoRa Alliance [Internet]. 2021 [cited 2021 Sep. 17]. Available from: https://lora-alliance.org/

[26] Ragnoli M, Barile G, Leoni A, Ferri G, Stornelli V. An autonomous low-power lora-based floodmonitoring system. Journal of Low Power Electronics and Applications. 2020; 10(2): p. 15.

[27] ESP8266-07 [Internet]. 2021 [cited 2021 Sep. 17]. Available from: https://ozdisan.com//kablosuz-veiot-cozumleri/rf-moduller/wifi-modulleri/ESP826607

[28] Mosfet Nedir? Çeşitleri, Özellikleri [Internet]. 2021 [cited 2021 Sep. 17]. Available from: http://www.robotiksistem.com/mosfet_nedir_mosfe t_cesitleri.html

[29] Narayana S, Prasad R. V, Rao V. S, Prabhakar T. V, Kowshik S. S, Iyer M. S. PIR sensors: Characterization and novel localization technique. 14th international conference on information processing in sensor networks. 2015. p. 142-153.

[30] ACS712 Datasheet [Internet]. 2021 [cited 2021 Sep. 17]. Available from: https://www.alldatasheet.es/datasheetpdf/pdf/168326/ALLEGRO/ACS712.html

[31] DS1302 Datasheet [Internet]. 2021 [cited 2021 Sep. 17]. Available from: https://datasheets.maximintegrated.com/en/ds/DS13 02.pdf

[32] KiCad EDA [Internet]. 2021 [cited 2021 Sep. 17]. Available from: https://www.kicad.org

[33] Tang K, Wang Y, Liu H, Sheng Y, Wang X, Wei Z. Design and implementation of push notification system based on the MQTT protocol. International Conference on Information Science and Computer Applications, ISCA 2013. pp. 116-119. 